\title{
Enhancing Higher Education Practice Through the 3D Pedagogy Framework to Decolonize, Democratize and Diversify the Curriculum
}

\author{
Deborah Gabriel \\ Bournemouth University \\ United Kingdom
}

\begin{abstract}
The 3D Pedagogy Framework is a strategic model of inclusive teaching practice developed to decolonize, democratize and diversify the higher education curriculum. In the UK, USA and elsewhere, an attainment gap exists between and among White students and students of colour. The 3D Pedagogy Framework targets education practice as the primary driver for enhancing the experience and outcomes of students of colour and enriching the learning process for students of all ethnic and cultural backgrounds. This paper discusses a pilot study involving 27 educational practitioners that undertook a workshop on 3D Pedagogy. Preliminary findings from quantitative and qualitative data collected point to the efficacy of the 3D Pedagogy Framework as an effective model for enhancing the cultural competencies of educational practitioners and promoting critical reflection and agency; important steps towards transforming the curriculum.
\end{abstract}

\section{Introduction}

Equality, diversity and inclusion in teaching and learning practice are increasingly important dimensions of higher education. In the UK, the proportion of students from Black and minority ethnic backgrounds has increased over the past decade from $16 \%$ in the $2004 / 5$ academic year, to $22 \%$ in $2016 / 17$ [1]. However, the rise in ethnic diversity has not met with institutional cultural change, which contributes to racial disparities for students that do not fit the dominant cultural model [2]. Black students experience higher levels of alienation than students from other ethnic groups and do not feel the curriculum reflects wider societal issues around race, equality, and diversity [3]. Mainstream curricula continue to predominantly reflect the socio-historical experiences of White, middle and upper-class males [4], [5].

In 2012, the National Union of Students [6] in the UK, called for a 'liberated' curriculum that challenges and tackles structural inequalities in society, alongside equality and diversity. Since then government changes to the higher education (HE) sector have brought greater scrutiny of educational disparities linked to attainment and progression through a new regulatory body, the Office for
Students. In addition, education practice and student outcomes are key drivers of the Teaching Excellence Framework, through which the quality of teaching is evaluated, shaping the ranking and positioning of institutions in league tables. Students continue to call for radical changes to the curriculum through a multifaceted approach that focuses on teaching materials, course content, delivery and assessment, to create a more inclusive learning environment [6]. To meet student demands and government priorities, HE institutions must ensure educational practitioners have the requisite skills to deliver culturally democratic teaching and create inclusive learning environments in which all students can flourish. Research suggests that transforming the curriculum to create a more inclusive teaching and learning environment not only enhances the experience of students of colour, but yields benefits to a wide demographic, since students that are exposed to diverse cultures and perspectives are more politically engaged and civic-minded [7]. A more diverse curriculum also helps students to develop the cultural competencies that can enhance access to global career opportunities in today's internationalized employment markets [8].

\section{Racial disparities in higher education}

In the UK, longstanding disparities exist in relation to the degree attainment gap between and among White students and students of colour. This gap is widest among Black students, with recent data revealing that while $78.8 \%$ of White students gained a good degree ( $1^{\text {st }}$ class or upper second), only $53.1 \%$ of Black students achieved this compared with $63.2 \%$ overall, for students of colour [9]. Racial disparities in student attainment is not confined to the UK. In the US, for example, only $14 \%$ of Black adults and $11 \%$ of Latinos hold a bachelor's degree compared with $23.7 \%$ of White adults Furthermore, 14\% of White Americans hold an advanced degree compared with just $8.5 \%$ of African Americans and while $2.1 \%$ of Whites hold a doctorate, the figure is $1 \%$ for African Americans [10]. In addition to students of colour being less likely to obtain a good degree in the UK, they are also less satisfied with their overall university experience [3]. This must be seen not only as a 
contributory factor to disparate educational outcomes but part of a wider pattern of racial inequality within higher education. Factors that impact student attainment and satisfaction include a sense of belonging; the curriculum; social capital and support [11]. Social belonging, is defined as a basic human need that individuals experience as feeling socially connected, has been linked to academic achievement. Students from groups that are negatively stereotyped and stigmatized, such as racial minorities, have a greater sensitivity towards social belonging. My own research [12] posits that a student's sense of belonging is negatively impacted by the exclusion or marginalization of their cultures within the curriculum. Every cultural reference, from 'classical' music to 'modern languages' is synonymous with 'European' [13]. This is often compounded by a lack of cultural competence from predominantly White, middle class teaching staff who are oblivious to the alienation students of colour experience within the institutional environment. These students are constantly bombarded with stereotypical representations of their racialised identities in and through the media, popular culture, interactions with others and often in the literature from which course content is drawn. This is due in part to the research that informs teaching practice since 'most research is premised on western, Eurocentric paradigms that speak to 'Eurocentric ideological and philosophical worldviews.' [5] Learning, teaching and assessment practices can also contribute to the attainment gap. This includes low teacher expectations, the underchallenging of students of colour, biased attitudes and perceptions around language competence and discriminatory practices in relation to teaching, assessment and student support. This has created an 'an urgent need to develop a more inclusive HE curriculum' [14] which can help create a more inclusive learning experience for all students.

Bensimon [15] argues that racial disparities in higher education attainment reflect learning deficiencies on the part of institutions, rather than students. Racial disparities in educational attainment are too often attributed to historic, stereotypical, racial ideologies that equate intellect and achievement with Whites and Asians and deficit and under-achievement with Black and Hispanic communities. Addressing such racial disparities necessitates social actors within HE institutions shifting their way of thinking about racially marginalized students 'through the lens of equity'. This involves reflecting on how we teach, our perceptions of how students learn, and assumptions made about students based on race and ethnicity - all of which shape student outcomes. Racial disparities in educational achievement should therefore be conceptualized as a learning problem on the part of individual institutional actors - lecturers, professional staff, faculty members, administrators and the cognitive frames ('interpretative frameworks through which individuals understand and make sense of phenomenon' [15] that shape their attitudes, beliefs, values and actions. Diversity-minded educators may be aware of racial and ethnic diversity and perceive themselves as progressive but tend to attribute the attainment gap as natural based on the culture and socio-economic backgrounds of the students. By contrast, equity-minded educators have a critical consciousness about racial inequality and are more likely to attribute the attainment gap to historic experiences of exclusion and marginalization. The importance of the distinction between the two cognitive frames is that diversity-minded educators are more likely to adopt a deficit approach, rather than focus on pedagogy.

\section{Pedagogies of social justice}

Social justice education is built on the principle that education is a site where democratic ideals should be embraced and practiced with the aim of bringing about social change in society [16]. Freire [17] argued that education should facilitate social justice by helping the oppressed develop critical consciousness to understand the structures of domination and imagine alternative possibilities. Building on Freire's work, contemporary social justice educators posit that educational environments should be spaces that facilitate 'engaged, critical and empowered thinking $\&$ action' that aim to address societal issues 18]. A culturally democratic curriculum is a key component of social justice education, important in the development of cultural competencies by drawing on the variety of cultural perspectives and knowledge systems that shape world views [4].

Arguably, social justice education is incomplete without the inclusion of critical examinations of race, given the pervasiveness of racism in global societies [19]. White racial power and privilege are deeply embedded in higher education. Incorporating racism and White privilege into curriculum design can enable students from all ethnic backgrounds to develop a deeper understanding of racism [20]. White European epistemologies, ontologies and axiologies are deeply embedded within every sphere of society to the extent that White, western thought is always centralized and determines how knowledge is created, defined and validated [21]. Helping educators-especially from White, middle class backgrounds, to develop cultural competence and critical understandings of race can help to enhance their education practice by developing greater empathy and connectedness with students of colour. The ability to relate more deeply with students of colour can help educators develop a more culturally relevant curriculum [22]. 


\section{The 3D Pedagogy Framework}

This is a strategic model of inclusive teaching practice I have developed over the past four years to decolonize, democratize and diversify the UK higher education curriculum. It evolved through my own teaching practice as a fusion of social justice pedagogy, critical race pedagogy and critical reflective practice. Decoloniality is a critical standpoint and movement with origins in south and Latin America, led by indigenous and Afrodescendant scholar-activists. Their key objectives are not only to challenge Eurocentric modes of thinking inextricably linked to slavery, colonialism and modernity, but to construct and advance new ways of thinking, knowing and doing from the intellectual production that emerges from the lived experience of the colonized [23]. 'Democratization' within the 3D Pedagogy Framework refers to cultural democracy, defined as the principle that all ethnic and cultural groups should 'be active participants in the world with an equal right to the cultural, economic and political power available within society' [4]. In the context of higher education this means looking beyond Eurocentric modes of thinking to include other epistemologies that have contributed to human development. Critical reflective practice is a fusion of critical inquiry, self-reflection and critical analysis. Critical reflective practitioners seek to transform power relations in learning and teaching environments in ways that empower students [24]. 'Diversification' is an essential component of cultural democracy and refers to an inclusion within the curriculum of global and diverse cultural perspectives in course content and teaching and learning styles. Social justice pedagogy has been discussed in section 1.2 of this paper. The final component of the 3D Pedagogy Framework, critical race pedagogy, has its origins in the work of Ladson-Billings [25] and Marvin Lynn [26]. Critical race pedagogy is concerned with integrating race and culture with critical pedagogy to deliver culturally relevant teaching with emancipatory objectives. It has evolved and is grounded in the socio-historic experiences of African American students and educators.

In 2014/15 I designed a new final-year undergraduate module for degrees offered through the Faculty of Media and Communication. My objectives were to help students critically engage with historical and contemporary issues around race, ethnicity and culture and their relationship with power across the media and in communications practice with the specific aim of facilitating their development of cultural competencies that can be applied in a professional context to a range of communication industries. The unit ran in 2016/17 for the first time and in 2017/18. For both years I collected quantitative data in the form of an end-of-unit survey to evaluate student perceptions of critical consciousness, cultural competence and agency, after completing the unit. The findings from two years of data saw students report high levels of critical consciousness and agency and self-perception of greater levels of cultural competence [2]. The unit was commended by the External Examiner in both academic years for pedagogic innovation and delivery and for both years I received student awards that made specific mention of the unit and its focus on social justice and equality. I was keen to extend the positive impact of my pedagogical approach beyond my own students, and beyond the UK. I shared my education practice and research with the international academic community at education conferences in Hawaii, Washington DC, New York and Austin, Texas, between 2016 and 2018 and the positive feedback and engagement led me to develop the 3D Pedagogy Framework. After a successful application for an early career researcher prime funding award from my institution, I developed the 3D Pedagogy workshop which I piloted at two universities in the UK and at the Canada International Conference on Education (CICE) at the University of Toronto in June 2018. I will now report the findings of this research.

\section{Methods}

\subsection{Research Objectives}

This study aimed to evaluate the effectiveness of a workshop based on the 3D Pedagogy Framework designed to enhance education practice through decolonization, democratization and diversification of the curriculum. The specific aims of the workshop were to:

4. Enhance the cultural competence of educational practitioners.

5. Equip educators with the knowledge and skills to decolonize, democratize and diversify and the curriculum through critical and emancipatory pedagogies.

6. Enhance education practice through critical reflective practice.

\subsection{Sample and workshop description}

The 3D Pedagogy Workshop was delivered at three locations. Two of the workshops took place in the Media Schools at two UK universities in May 2018. An information leaflet was created and circulated to potential staff through Professors within the schools providing information about the workshop and inviting participation. A total of nine staff members were recruited through this method. The roles of the staff members included learning technologist, lecturer, senior lecturer and professor. The UK workshops lasted for 210 minutes. 
The third workshop was delivered at CICE in June 2018 to 17 Participants from six countries including the US, Canada, New Zealand, South Africa, The Philippines and United Arab Emirates. The roles of the participants were varied with some members working in the primary and secondary sectors, as well as in higher education. The workshop lasted for 90 minutes.

\subsection{Workshop content and format}

The workshop is comprised of four interactive themed sessions: The 3D Pedagogy Framework, Social Justice Pedagogy, Critical Race Pedagogy and Critical Reflective Practice. Participants were supplied with post-it-notes or blank postcards to record their responses to a series of questions. After writing down their responses, participants were invited to share them with the group, which were recorded on a whiteboard, discussed collectively, and compared with examples I shared of conceptualizations derived from the literature. Responses recorded by participants on post-it-notes and postcards were collected and recorded on a spreadsheet and will be used to develop an electronic teaching resource.

\section{$\underline{\text { Workshop Questions }}$}

Q1: What does decolonization mean to you?

Q2: What does democratization mean to you?

Q3: What does diversification mean to you?

5.3.1. Case Study on social justice pedagogy \& critical race pedagogy. After discussion around the 3D Pedagogy Framework, I presented a case study (my final year undergraduate module referenced in section 1.3) to illustrate how to design a module integrating social justice pedagogy and critical race pedagogy.

5.3.2. Critical reflective practice. After appraising participants of the schools of thought around critical reflective practice, participants were asked to write down one thing they would take away from the workshop and apply to their future teaching practice.

5.3.3. Data collection. Following the workshops, participants were emailed the link to an online survey for completion and 12 responses were received. It was originally intended that focus group discussions after the workshops to allow participants to reflect on their learning would form part of the data collection. However, due to the time constraints at CICE, where focus group discussions were not possible, the decision was taken to exclude focus group discussions that took place in the UK from the data analysis. Similar discussions took place with participants at the CICE conference, over the duration of the conference, with some of the participants. While these informal discussions provided a space for reflection and general discussion about the curriculum, it was decided to limit the data to the specific questions asked of all participants during the workshop and as part of the survey, for consistency.

\subsection{Conceptual Approach}

The conceptual approach to this research is experiential learning, defined as 'the process whereby knowledge is created through the transformation of experience' [27]. A dimension of experiential knowledge that has emerged from experiential learning theory which has particular relevance to the interactive workshop is 'conversational learning' [28] This is based on the premise that people learn from each other to create new knowledge through the medium of conversation. Conversations are conceptualized as social experiences that generate new ways of seeing the world. The two dimensions of conversational learning involve personal knowledge, acquired through personal experiences and social knowledge that emerges from ideas generated through texts and experiences and shared in conversations. The workshop, with its interactive and participatory elements are dialogical and can therefore function as a conversational space and medium for learning and generating new knowledge.

\section{Findings}

\subsection{Survey responses}

Q1: Which of the following statements reflect your experience of the session on critical reflective practice?

Table 1. Critical Reflective Practice

\begin{tabular}{|l|l|}
\hline RESPONSE & $\%$ \\
\hline $\begin{array}{l}\text { I gained insights into how } \\
\text { critical reflective practice } \\
\text { can be embedded into the } \\
\text { curriculum. }\end{array}$ & $41.7 \%$ \\
\hline $\begin{array}{l}\text { I reflected on some the ways } \\
\text { that I'm already incorporating } \\
\text { critical reflective practice } \\
\text { into my teaching. }\end{array}$ & $75 \%$ \\
\hline $\begin{array}{l}\text { I reflected on some of the } \\
\text { challenges of engaging in } \\
\text { critical reflective practice. }\end{array}$ & $50 \%$ \\
\hline $\begin{array}{l}\text { I thought of new ways I can } \\
\text { use critical reflective } \\
\text { practice to enhance my } \\
\text { teaching. }\end{array}$ & $58.3 \%$ \\
\hline
\end{tabular}


Q2: Which of the following statements reflect your experience of the session on critical race pedagogy?

Table 2. Critical Race Pedagogy

\begin{tabular}{|l|l|}
\hline RESPONSE & $\%$ \\
\hline $\begin{array}{l}\text { I gained insights into how } \\
\text { critical race pedagogy can be } \\
\text { embedded into the curriculum. }\end{array}$ & $66.7 \%$ \\
\hline $\begin{array}{l}\text { I reflected on some the ways } \\
\text { that I'm already incorporating } \\
\text { critical race pedagogy into my } \\
\text { teaching. }\end{array}$ & $50 \%$ \\
\hline $\begin{array}{l}\text { I reflected on some of the } \\
\text { challenges of embedding } \\
\text { critical race pedagogy into my } \\
\text { teaching. }\end{array}$ & $41.7 \%$ \\
\hline $\begin{array}{l}\text { I thought of new ways I can } \\
\text { use critical race pedagogy to } \\
\text { enhance my teaching. }\end{array}$ & $41.7 \%$ \\
\hline
\end{tabular}

Q3: Which of the following statements reflect your experience of the session on social justice pedagogy?

Table 3. Social Justice Pedagogy

\begin{tabular}{|l|l|}
\hline RESPONSE & $\%$ \\
\hline $\begin{array}{l}\text { I gained insights into how } \\
\text { social justice pedagogy can be } \\
\text { embedded into the curriculum. }\end{array}$ & $91.7 \%$ \\
\hline $\begin{array}{l}\text { I reflected on some the ways } \\
\text { that I'm already incorporating } \\
\text { social justice pedagogy into } \\
\text { my teaching }\end{array}$ & $50 \%$ \\
\hline $\begin{array}{l}\text { I reflected on some of the } \\
\text { challenges of embedding social } \\
\text { justice pedagogy into my } \\
\text { teaching. }\end{array}$ & $50 \%$ \\
\hline $\begin{array}{l}\text { I thought of new ways I can } \\
\text { use social justice pedagogy to } \\
\text { enhance my teaching. }\end{array}$ & $33.3 \%$ \\
\hline
\end{tabular}

Q4: Which of the following statements reflect your understanding of the 3D Pedagogy Framework?

Table 4. 3D Pedagogy Framework

\begin{tabular}{|c|c|}
\hline RESPONSE & $\%$ \\
\hline $\begin{array}{l}\text { I have an excellent } \\
\text { understanding of what } \\
\text { decolonization, } \\
\text { democratization and } \\
\text { diversification means in } \\
\text { relation to the higher } \\
\text { education curriculum. }\end{array}$ & $25 \%$ \\
\hline $\begin{array}{l}\text { I have a very good } \\
\text { understanding of what } \\
\text { decolonization, }\end{array}$ & $58.3 \%$ \\
\hline
\end{tabular}

\begin{tabular}{|l|l|}
\hline $\begin{array}{l}\text { democratization and } \\
\text { diversification means in } \\
\text { relation to the higher } \\
\text { education curriculum }\end{array}$ \\
\hline $\begin{array}{l}\text { I have a satisfactory } \\
\text { understanding of what }\end{array}$ & $8.3 \%$ \\
decolonization, & \\
democratization and & \\
diversification means in & \\
relation to the higher & \\
education curriculum. & \\
\hline $\begin{array}{l}\text { I do not understand what } \\
\text { decolonization, }\end{array}$ & $8.3 \%$ \\
democratization and & \\
diversification means in & \\
relation to the higher & \\
education curriculum. & \\
\hline
\end{tabular}

Q5: Do you think you will apply any of what you have learnt to your own teaching?

Table 5. Applying the Knowledge

\begin{tabular}{|l|l|}
\hline RESPONSE & $\%$ \\
\hline Yes & $91.7 \%$ \\
\hline Not Sure & $8.3 \%$ \\
\hline
\end{tabular}

Q6: Would you be interested in joining a 3D Pedagogy Framework Research Network to undertake collaborative research?

Table 6. Building a Teaching Community

\begin{tabular}{|l|l|}
\hline RESPONSE & $\%$ \\
\hline Yes & $75 \%$ \\
\hline Not Sure & $25 \%$ \\
\hline
\end{tabular}

Q7: Additional Comments

\section{Table 7. Additional Comments}

The workshop was great to be part of. Definitely want to join the network. Many thanks for all your hard work.

I found the workshop useful and inspiring, because it's easy to apply the principles to individual areas of teaching.

This was immensely inspiring and thought provoking! I think you should aim higher with this and expand this across lots of disciplines beyond media as it can be applicable across social science, science and arts and humanities.

Thank you, Deborah! Your session was fantastic, and I learned so much from our discussions. Looking forward to working with you.

Would love to cite your 3D Pedagogy Framework in my sabbatical report. 


\subsection{Workshop responses}

Q: What will you take away from this session to apply to your educational practice?

Table 8. Ways to Apply the Knowledge

Review module reading list and consider the perspectives represented; find additional voices that expand, enrich and challenge the current narrative.

Link student narratives/positions to content via coproduction/open approaches to content

Using assessment as a means to critique norms and power/dominance.

Foreground difference from the beginning of the module.

Be self-reflective about own positioning.

Diverse perspectives in my subject enables students to be engaged and feel a sense of belonging - part of integration in education.

Consider the order that we present knowledge - i.e. the White version of history then indigenous history as an 'alternative'.

Share critically reflective practice with my colleagues 3D Pedagogy.

I will take away the idea of democratizing the curriculum and can think of examples from feminist methodology.

Encourage critical reflective practice and use the 3Ds as part of my critical thinking.

Use different ethnic names in my exam questions as well as cities from different parts of the world.

The importance of checking in with my learners often to make sure I am more than a uni-lens of the topic we are discussing.

Global Advertising Practice - developing models based on global practice.

\subsubsection{Additional comments collected at workshop.}

Table 9. Final Comments

Thanks for an inspiring workshop.

Great session Deborah - I'm in gratitude!

I found it helpful and very inspiring.

I really enjoyed the time and it was a great workshop to be part of.

Thanks again for today's incredibly useful and inspiring workshop. The session addressed the anxieties I've experienced in the classroom regarding how to approach and tackle issues of 'race' and white privilege. It's provided a model through which I can democratize my teaching but one which is incredibly constructive and positive too.

\section{Discussion}

The 3D Pedagogy workshop was designed as an interactive learning strategy to engender critical reflection among participants throughout the session. In addition to promoting critical enquiry, it also functioned as a supportive learning community in which participants shared best practice as well as the challenges they face in trying to embed ethnic and cultural diversity into the curriculum. Participants showed deep levels of engagement and enthusiasm throughout, seeing the workshop as constructive and of benefit in developing new approaches to enhance their education practice, as indicated in table 7 and table 9. This is consistent with previous research which suggests conversational learning is an effective 'medium for emotional, sensual, and physical engagement in the learning process' [28]. Similar responses were advanced by all three cohorts to questions on the meanings attached to decolonization, democratization and diversification. However, it was noted that the responses from the international cohort at CICE, were more nuanced, especially in discussions around race. For example, participants from the USA, Canada and New Zealand were very conscious of the impact of colonization and historical racial injustice and expressed a responsibility to 'undo colonization' and 'include indigenous knowledge' and 'other cultural perspectives'. This emotional investment helped promote deep learning and is consistent with experiential learning theory, which posits that 'Emotion holds the key to a higher level of learning, through reflective dialogue' [29]. The survey findings suggest that most participants gained new insights and reflected on their existing teaching practice. However, the most significant outcome of the workshop was the high proportion of participants $(91.7 \%)$ who said they would apply what they learnt to their teaching practice. Table 8 provides further evidence that the workshop promoted deep learning as the participants listed very specific tasks related to modules they teach on, rather than general expressions of commitment. Overall, the findings point to the efficacy of the 3D Pedagogy Framework as an effective strategy for enhancing educational practice, through four levels of impact:

1. Changing practice in higher education.

2. Impact on curriculum design

3. Impact on practitioner's reflective practice.

4. Wider impact in education.

\section{Conclusion}

Racial disparity in higher education attainment is a pervasive and persistent inequality across the UK, US, Canada, South Africa, Australia, New Zealand and beyond. Whilst the causes are varied and complex, race remains a major determinant of educational outcomes. In the $21^{\text {st }}$ century it is no longer plausible or acceptable to attribute the cause to cultural differences or socio-economic status. Bensimon [15] argues that racial disparities in higher education attainment reflect learning deficiencies on the part of institutions, rather than students and suggests addressing such racial disparities 
necessitates social actors within $\mathrm{HE}$ institutions shifting their way of thinking about racially marginalized students 'through the lens of equity'. Such a process involves reflecting on how we teach, our perceptions of how students learn, and assumptions made about students based on race and ethnicity, with the aim of developing 'equity-minded' educators. Preliminary findings from the 3D Pedagogy Workshop suggests that the framework upon which it is based, and the mode of delivery can help to achieve this goal. Critical inquiry and selfreflection are two key components of reflective teaching practice. The former involves moral and ethical analysis of how our actions in the classroom impact students. The latter involves analysis of how our personal values and beliefs are inextricably embedded into assumptions we make about our students and our expectations of them. The findings from this study point to the efficacy of conversational learning as an effective medium for promoting deep learning, creating a supportive and collaborative learning environment, and promoting agency. In addition to enhancing education practice, the 3D Pedagogy Framework can potentially fulfil emancipatory goals by creating an inclusive teaching and learning environment in which all students can flourish.

\subsection{Next steps}

This pilot study reflects the findings of data collected during and following the 3D Pedagogy Workshop and the intention of participants to apply the new knowledge to their teaching practice. Followup studies are planned to collect further qualitative data from the participants to learn how they changed their teaching practice and what impact this has had on student outcomes and the student experience.

The overall aim of this research is to develop an effective, strategic approach to enhance education practice and improve the experience and outcomes for students of colour, while enriching the learning environment for students of all ethnic and cultural backgrounds.

\section{References}

[1] HESA. 2015. 2013/14 First Year Students By Ethnicity. Retrieved from https://www.hesa.ac.uk/free-statistics

[2] Gabriel, D. (2018). Pedagogies of social justice and cultural democracy in media higher education. Issue $8.1 \mathrm{pp}$. 34-MERJ

[3] NUS (2011). Race for Equality: a report on the experiences of Black students in further and higher education. London: NUS.

[4] Aldridge, D. P. (2000). On race and culture: Beyond Afrocentrism, Eurocentrism to cultural democracy. Sociological Focus, 33 (1): 95-107.
[5] Blay, Y., 2008. All the 'Africans' Are Men, All the 'Sistas' are 'American' But Some Of Us Resist: Realising African Feminism(s) as an Africological Research Methodology. In: Journal of Pan African Studies. 2(2),5873.

[6] NUS (2012). Liberty, Diversity and Equality in the Curriculum.

[7] Bowman, N.A., 2011. Promoting Participation in a Diverse Democracy: A Meta-Analysis of College Diversity Experiences and Civic Engagement. In: Review of Educational Research. 81(1), 29-68.

[8] Sims, M., 2007. Not Enough Understanding: Student Experiences Of Diversity in UK Universities. London: Runnymede.

[9] Equality Challenge Unit, 2017. Equality in higher education students statistical report 2017. London: Equality Challenge Unit.

[10] US Census Bureau. 2016.

[11] Hefce, (2015) Causes of differences in student outcomes University of Manchester.

[12] Gabriel, D. (2016). Race, Racism and Resistance in British Academia in A Critical Study of (Trans) National Racism: Interdependence of Racist Phenomenon and Resistance Forms. (eds.), Fereidooni, K \& El, M. Wiesbaden: SpringerVS, pp.493-505.

[13] Asante, M. K. (2006). A discourse on Black Studies. Journal of Black Studies, 36(5):646-662.

[14] Singh, G. (2011:30) Black and minority ethnic (BME) students' participation in higher education: improving retention and success. A synthesis of research evidence. York: HEA.

[15] Bensimon, E.M., (2005:100-101). Closing the achievement gap in higher education: An organizational learning perspective. New directions for higher education, (131), pp.99-111.

[16] Mthethwa-Sommers, S., 2014. What Is Social Justice Education? In: Somers, S, ed, Narratives of Social Justice Educators. Springer International Publishing, 7-23.

[17] Freire, P (1970/1994) Pedagogy of the Oppressed. New York: Continuum.

[18] Hackman, H. (2006:13). Five essential components for social justice education. Equity and Excellence in Education. Vol.38, 103-109.

[19] Kumagai, A.K., and Lypson, M.L., 2009. Beyond Cultural Competence: Critical Consciousness, Social Justice, and Multicultural Education. In: Academic Medicine. 84 (6), 782-787.

[20] Bell, LA., Love, B.J., and Roberts, A. (2007). 'Racism and white privilege Curriculum Design. In Teaching for Diversity and Social Justice, 123-144. 
[21] Scheurich, J.J \& Young,.M.D.(1997). Coloring epistemologies: Are our research epistemologies racially biased? Educational Researcher. 26(4):4-16

[22] Picower, B., 2009. The unexamined whiteness of teaching: How white teachers maintain and enact dominant racial ideologies. Race Ethnicity and Education, 12(2), pp.197-215.

[23] Walsh, C., 2012. " Other" Knowledges," Other" Critiques: Reflections on the Politics and Practices of Philosophy and Decoloniality in the" Other" America. Transmodernity, 1(3), pp.11-27.

[24] Larrivee, B. (2000). Transforming teaching practice: Becoming the critically reflective teacher. Reflective practice, 1(3), 293-307.

[25] Ladson-Billings, G., 1995. Toward a theory of culturally relevant pedagogy. American educational research journal, 32(3), pp.465-491.

[26] Lynn, M., 1999. Toward a critical race pedagogy: A research note. Urban education, 33(5), pp.606-626.

[27] Kolb, D. A. (1984:41). Experiential learning: Experience as the source of learning and development. New Jersey: Prentice-Hall.

[28] Brockbank, A, Mc Gill, I (1998) Facilitating Reflective Learning in Higher Education; Buckingham; SRHE \& OUP; 